\title{
Der Zahn der Zeit zernagt nicht nur ... er kann auch packend festhalten, was vom Vergessen und Verschwinden bedroht ist
}

Jürg Kesselring

Korrespondenz:

Prof. Dr. med. Jürg Kesselring Rehabilitationszentrum

$\mathrm{CH}-7317$ Valens

Tel. 0813031408

Fax 0813031410

juerg.kesselring[at]

klinikenvalens.ch
«The Swerve» ist ein ungewohntes Wort im Englischen: «eine Seitwärtsbewegung machen, abweichen, abschweifen, Ziel aus den Augen verlieren, Effet geben ...». Es geht um eine Weichenstellung, die der Harvard-Anglist und mehrfache Preisträger Stephen Greenblatt für unsere Geistesgeschichte dort sieht, wo der päpstliche Sekretär (secretus) und Bücherjäger Poggio Bracciolini im Winter 1417 in einem nicht näher identifizierbaren Kloster (wahrscheinlich Fulda) das Manuskript «De rerum natura» von Lukrez findet und durch Abschriften wieder in die Welt bringt, aus der es durch verschiedenste Absichten und Machenschaften für mehr als tausend Jahre verbannt gewesen war [1].

Seine Klarheit «Der Tod berührt uns nicht» artikuliert einen Gedanken, den zu fassen - und wenn auch nur innerlich - so lange Zeit nicht erlaubt war: dass es manipulativ und grausam ist, anderen Angst einzuflössen (S. 19). In diesen kunstvollen Hexametern wird nämlich ausgeführt, dass es keinen Schöpfungsplan gebe, dass alle Dinge sich in riesigen Zeiträumen gebildet haben. Wie sich bei ihm ein philosophisch und wissenschaftlich leuchtender Geist mit einer ungewöhnlichen dichterischen Kraft verband, war damals (wie heute) eine Rarität, war man doch auch in Rom skeptisch gegenüber Philosophen und Dichtern als verweichlichten Kopfmenschen. Ernsthaftes Lesen war dort praktisch völlig aufgegeben worden, der Verlust kultureller Verankerung führte in fiebrige Trivialität oder langweilige Untätigkeit, zu seichtem Geklimper und Possenreisserei. Wie fremd (und gefährlich) musste die von Lukrez vertretene und ausgeführte Lehre von Epikur gelten, die eine Lebensfreude durch Genuss und Genügsamkeit empfahl, der es wichtig war: klug, ehrenwert, gerecht zu sein, mutig, mässig und grossmütig, nach der es wichtig war, Freunde zu haben und wohltätig zu sein. Hier war Geselligkeit und Dialog gefragt, Gedankenaustausch mit Witz und Ernsthaftigkeit, mit Charme und Abwechslung, Raum lassend für abweichende Ansichten, gelassen und nicht rechthaberisch.

So mussten denn die strengen Kirchenväter wie Hieronymus alles daran setzen, wahre Christen abzuschrecken, solche heidnischen Philosophen zu lesen, welche die angestrebte grosse kulturelle Transformation gefährden konnten, die aus dem Streben nach Lust zum Streben nach Schmerz führen sollte. Eine Begeisterung für die Erniedrigung und den
Schmerz ihres Gottes sollte geschaffen werden. Laktanz schrieb in De ira Dei, dass das Zeichen seines Sich-Sorgens der Zorn sei: «Drum schlage er sie immer wieder mit eindrucksvoller, nie ermüdender Gewalt - was man nicht fürchtet, schätzt man gering». Genuss wurde zum Laster dekretiert, dem zornigen Gott musste ein Schmerzenszoll entrichtet werden.

All dies wird auch illustriert in den Schilderungen der wirbelnden, aufgeblähten Machtsphäre beim Konzil von Konstanz, wohin Poggio den Papst Johannes XXIII. begleitet hatte, der dort als einer von drei Päpsten abgesetzt wurde und so den Namen unfreiwillig freigab, der in diesen Tagen der Heiligsprechung in ganz anderen Zusammenhängen dient ... Poggio hatte diese Vorgänge und Ansprüche der absoluten Herrscher mit ihrer dogmatischen Religion sehr genau beobachtet (er diente insgesamt acht Päpsten!), diese theatralische Prätention von Heiligkeit und die betrügerische Nutzung von Orakeln aus heidnischen Religionen, mit denen das gemeine Volk sich einschüchtern und manipulieren liess. «Ich muss alles versuchen, um es zu etwas zu bringen, damit ich nicht länger Herren zu Diensten sein muss und Zeit habe für Literatur». Bücher sind der Ausweg, die Flucht vor der alles durchdringenden Furcht, aus Verwirrung und Schmerz. Er setzte dies um «mit höchster Bildung und Sprachgewandtheit, mit einzigartiger Würde, Witz und Weltläufigkeit», wollte ausbrechen aus dieser augenfällig bekundeten Frömmigkeit, Demut und Weltverachtung, die durchmischt war mit Aggression und Pessimismus, Wut und Verzweiflung. Es war schwierig für ihn, ein Werk in die Welt zu entlassen, das sein gesamtes geistiges Universum in Frage stellte. Aber er wollte sich über Gleichgültigkeit ebenso erheben wie über einen vergifteten Aberglauben, der durch absurde Selbstüberschätzung und ebensolche Ängste eigentlich eine pöbelhafte Beleidigung der Götter war. Bei Lukrez hiess es, dass alles Seiende aus unsichtbaren Teilen zusammengesetzt sei und dass diese elementaren Teilchen, die Keime der Dinge seien: ewig, unendlich an der Zahl, begrenzt in Gestalt und Grösse und sich in unendlicher Leere bewegen. Alle Dinge entstehen infolge geringer Abweichungen, «einen kleinen Ruck» (das ist «The Swerve»): declinatio, inclinatio, clinamen.

Die Natur experimentiert unaufhörlich, es schafft sich das Geschaffene seine Funktion selbst. Das Universum ist weder wegen noch für die Menschen da. 
Das höchste Ziel des Lebens ist Steigerung des Genusses und Verringerung des Leidens. Die Seele ist sterblich: sie «verflüchtigt sich wie die Blume des Weines oder die Düfte des Salböls, die sich in die Lüfte entwinden». Der Tod berührt uns nicht. Religionen sind abergläubische Täuschungen, allesamt grausam. Es sind Phantasien der Rache und Vergeltung, von Angst und Perversionen, z.B. die endlos wiederholten, stets prominent zur Schau gestellten Bilder blutig ermordeter Kinder durch die Eltern das wurde um 50 Jahre vor unserer Zeitrechnung geschrieben. «Das Verstehen der Dinge und ihrer Natur weckt grosses Staunen. Mit Hilfe der Poesie kann in seiner wirklichen Pracht dargestellt werden, was die Dinge wirklich sind ...» und er endet, wie wir: «voller Staunen und Dankbarkeit».

Montaigne bringt in seinen Essais fast hundert Zitate aus Lukrez [2]. Auch er verachtet eine Moral, die man glaubt mit Albträumen aus dem Jenseits herbeizwingen zu müssen, weist die fromme Furcht zurück, verachtet jeden religiösen Fanatismus und verabscheut jede Grausamkeit. In seiner Konzentration auf die Welt bewundert er das Einfache und Natürliche, hat ein Verständnis für die animalische Natur des Menschen und ein Mitgefühl auch mit allen anderen Arten der Tierwelt. Er wollte (und konnte) unbesorgt um den Tod sterben - «den Läufern gleich die Fackel weitergeben».

\section{Literatur}

1 Greenblatt S. The Swerve. How the World became modern (Orig.). Die Wende. Wie die Renaissance begann. München: Pantheon; 2013.

2 Bakewell S. Wie soll ich leben? Oder das Leben Montaignes in einer Frage und zwanzig Antworten. München: C.H Beck; 2013. 